\title{
Cumulative Effect of Temperature and Solar Radiation on Wheat Yield
}

\author{
Mukhtar AHMED*, Fayyaz-ul HASSAN \\ PMAS-Arid Agriculture University, Department of Agronomy Rawalpindi, Pakistan; ahmadmukhtar@uaar.edu.pk (*corresponding author)
}

\begin{abstract}
The impact of temperature and solar radiations were studied as determinant factor for spring wheat grain yield. The data obtained at anthesis and maturity for grain number $(\mathrm{GN})$, grain weight $(\mathrm{GW})$ and grain yield $(\mathrm{Y})$ were examined with mean temperature at anthesis (T1) and maturity (T2), solar radiation at anthesis (SR1) and maturity (SR2) and photothermal quotient (PTQ) at anthesis (PTQ1) and maturity (PTQ2). The data obtained was subjected to Statistica 8 software and scatter plot regression model was developed at 95\% confidence interval with crop data and climate variables (T1, T2, SR1, SR2, PTQ1 and PTQ2). Results clearly indicated that yield remained directly proportional to solar radiation and temperature plus solar radiation (PTQ) while inversely to temperature under optimum other environmental resources. Direct relationship between PTQ and yield parameters confirmed that it determined crop yield and its management for variable environmental conditions need to be opted by adopting suitable sowing time as an adaptation strategy under changing climate.
\end{abstract}

Keywords: photothermal quotient, planting windows, solar radiation, temperature, wheat

\section{Introduction}

Climatic factors like temperature, solar radiation and rainfall effect crop yield all over the world. Changes in climatic variables like rise in temperature and decline in rainfall were reported by Intergovernmental Panel on Climate Change (IPCC, 2007). Pre anthesis and post anthesis high temperature and heat may have huge impacts upon wheat growth and stress reduced the photosynthetic efficiency of crop (Wang et al., 2011). Low temperature in the growing season may reduce germination and retard vegetative growth by inducing metabolic unbalances and can delay or prevent reproductive devolvement (Mohsen and Yamada, 1991). You et al. (2009) observed significant reduction in yield due to rise in temperature and it was concluded that with $1.8^{\circ} \mathrm{C}$ rise in temperature caused $3-10 \%$ reduction in wheat yields. Canopy temperature depression had an important role to explore physiological basis of grain yield of wheat (Bahar et al., 2008). The impact of climatic variables like temperature, solar ration and Photothermal Quotient (PTQ) could be assessed during crop life-cycle and by developing a quantitative relationship among climatic variables and crop yield. Significant change in yield of wheat due to variation in temperature and solar radiation has been observed (Ahmed et al., 2010; Li et al., 2010). Similarly, 0.6 to $8.9 \%$ reduction in wheat yield per $1{ }^{\circ} \mathrm{C}$ rise in temperature has been reported by Lobell and Field (2007). Meanwhile, selection of suitable genotypes under changing climatic scenarios must be evaluated which can be used in various regions of world (Akcura et al., 2005). Agricultural production is more complex because of the need to balance global food security, optimum production, technological innovation, preservation of environmental functions and protection of biodiversity (Ormerod et al., 2003). The ecological knowledge achieved in the present study enables considerable compliance with most of those objectives. Photothermal quotient (PTQ) can be defined as the ratio of total solar radiation in $\mathrm{MJm}^{-2} \mathrm{day}^{-1}$ to the mean daily temperature minus a base temperature $\left(4.5^{\circ} \mathrm{C}\right.$ for Spring Wheat). Nalley et al. (2009) identified, PTQ to improve the explanatory power of statistical regression models on grains per meter square (GM), grain weight (GW) and yield under climate change scenario. Similarly, direct relationships with PTQ and growth of wheat under different planting systems have been documented (Khichar and Niwas, 2007). However, Loomis and Amthor (1996) documented that crop growth and yield are derived from photosynthesis, dependent on receipt and capture of solar radiation. Hence studies are needed to understand and quantify the crop response and its relationship with varied combination of temperature and solar radiation to workout suitable planting windows for wheat. This is only possible if the canopies are tested under varying circumstances of temperature and radiation. The practical way to record such reading is to alter the sowing time of the crop within recommended growing season.

The objectives of this study were to evaluate the effect of mean temperature, total solar radiation and PTQ at anthesis and maturity stage of wheat crop during different environments (2008-09 and 2009-10) and thereafter to develop a regression model for climatic variables with grain weight, grains per meter square and yield of wheat crop for wide range of conditions. 


\section{Materials and methods}

The study was conducted at National Agriculture Research Center (NARC), Islamabad, Pakistan, located at latitude of $33^{\circ} 42^{\prime} \mathrm{N}$ and longitude of $73^{\circ} 10^{\prime} \mathrm{E}$. The soil series of study site was Rajar, with great groups Ustorthents and soil order Entisol. Five different planting windows (PW's) were used to provide variable climatic conditions at anthesis and maturity of wheat for two environments i.e. 2008-09 and 2009-10. The planting times were; PW1 (Sowing between 15 to 25 October), PW2 (Sowing between 26 October to 10 November), PW3 (Sowing between 10 to 20 November), PW4 (Sowing between 20 to 30 November) and PW5 (Sowing between 1 to 10 December) during both years (2008-09 and 2009-10). The experiments were laid out under Randomized Complete Block Design (RCBD), replicated four times in $4.5 \times 10$ $\mathrm{m}$ plot with row spacing of $25 \mathrm{~cm}$. Three wheat genotypes namely: 'Chakwal-50,' 'Wafaq-2001' and 'GA-2002' were planted. Sowing was done by hand drill using seed rate 50 $\mathrm{kg} / \mathrm{acre}$. Prior to sowing particular field remained fallow during summer which was ploughed once with soil inverting implement and thereafter thrice with tractor mounted cultivator. Recommended doses of fertilizer ( $\mathrm{N}$ and $\mathrm{P}$ ) $100 \mathrm{~kg} / \mathrm{ha}$ was added with last ploughing in the form of Urea and DAP.

Climatic data regarding temperature and solar radiation during the study period was collected from the weather station located at NARC. The mean temperature at anthesis (T1) and maturity (T2) was calculated by averaging all temperature from germination till anthesis and maturity respectively. Similarly, solar radiation at anthesis (SR1) and maturity (SR2) recorded with the Angstrom formula, which relates solar radiation to extraterrestrial radiation and relative sunshine duration (Allen et al., 1998).

The photothermal quotient calculated by Oritz-Monasterio et al. (1994) procedure and PTQ1 at anthesis by adding daily PTQs from germination to anthesis; PTQ2 at maturity by adding daily PTQs from germination to anthesis + anthesis to maturity. All genotypes at maturity were harvested and grain number per meter square $(\mathrm{GM})$, grain weight $(\mathrm{kg})$ and grain yield $\left(\mathrm{kg} \mathrm{ha}^{-1}\right)$ were measured.

\section{Statistical analysis and procedures}

The data obtained was subjected to Statistica 8 (Statsoft, Inc. 2007) software to develop a regression models among T1, T2, SR1, SR2, PTQ1 and PTQ2 with GM, $\mathrm{GW}$ and grain yield $\left(\mathrm{kg} \mathrm{ha}^{-1}\right)$. Scattered diagram can be used as linkage between environment and yield parameters as reported by Feiziasl et al. (2010). Two-dimensional scatterplots obtained envisaged a relation between two variables $\mathrm{X}$ and $\mathrm{Y}$ (e.g. T1 and GM). The regression analysis performed with confidence interval of $95 \%$.

\section{Results and discussion}

The temperature rise during crop growth cycle might result in seed abortion and reduced grain yield (IPCC, 2001). The results demonstrated that yield is dependent upon climatic variables and inverse correlation between anthesis temperature and grain numbers recorded in scatterplot diagram of grains per square meter against T1 (temperature at anthesis) (Fig. 1a). The maximum number of grains recorded between $18-20^{\circ} \mathrm{C}$ temperature having $\mathrm{R}^{2}(0.89)$. The regression equation obtained was GM $=5308.99+623.73(\mathrm{~T} 1)$ with 0.95 confidence interval. The results clearly indicated a strong relationship of anthesis temperature with grain number which may be further correlated with grain yield. Thus, at anthesis if optimum temperature available to crop, it may lead to good stand establishment. Similarly, response of grain weight with T1 depicted the maximum grain weight at $17^{\circ} \mathrm{C}$ with regression equation $(\mathrm{GW}=0.34+0.0037(\mathrm{~T} 1)$. The relationship between anthesis mean temperature and grain weight related positively $\left(\mathrm{R}^{2}=0.78\right)$ but upto optimum level (Fig. 1b). Further increase in temperature after optimum level may lead to shrinked grains resulting in lesser grain weight. Similarly, yield observed to be directly related with temperature at anthesis stage (Fig. 1c). Rise in temperature may have caused yield stagnation. The regression equation for yield in relation to $\mathrm{T} 1$ was $\mathrm{Y}=3284.7553-5.9702$ (T1). The decline in GM, GW and yield has been observed with increase in temperature from germination till maturity (T2) (Fig. 1d-f). The adverse effect of high temperatures on yields could partially be modified by preventive strategies including earlier sowing. The biological clock acceleration because of the increased temperature brought forward developmental stages and reduced the growing period between emergence and maturity. The regression equations obtained at 95\% confidence interval for GM, GW and grain yield was GM $=47367.06-1356.28(\mathrm{~T} 2)$, $\mathrm{GW}=1.05-0.02(\mathrm{~T} 2)$ and $\mathrm{Y}=4542.37-57.86(\mathrm{~T} 2) \mathrm{re}-$ spectively. The regression model showed a negative trend with unit increase in temperature from emergence to maturity. Similar findings have been documented in previous research. The significant negative trend of GM and GW with increased temperature revealed that crop growth and development adversely affected with increase in temperature. Maximum temperatures above $25^{\circ} \mathrm{C}$ significantly reduced grain weight Gate (2007) while Kalra et al. (2008) confirmed that wheat yields have fallen by 0.2-0.5 $\mathrm{t} \mathrm{ha}^{-1}$ per degree Celsius rise in temperature. Similarly, decrease in grain $\mathrm{m}^{-2}$ may be due to high temperature near heading. This phenomenon is similar to findings of Ahmed et al. (2011a and b) and Dawson and Wardlow (1989). They reported that high temperature during the pre-heading stage may have minimized pollen viability, resulting in less number of grains per spike. Present study highlighted that yield 


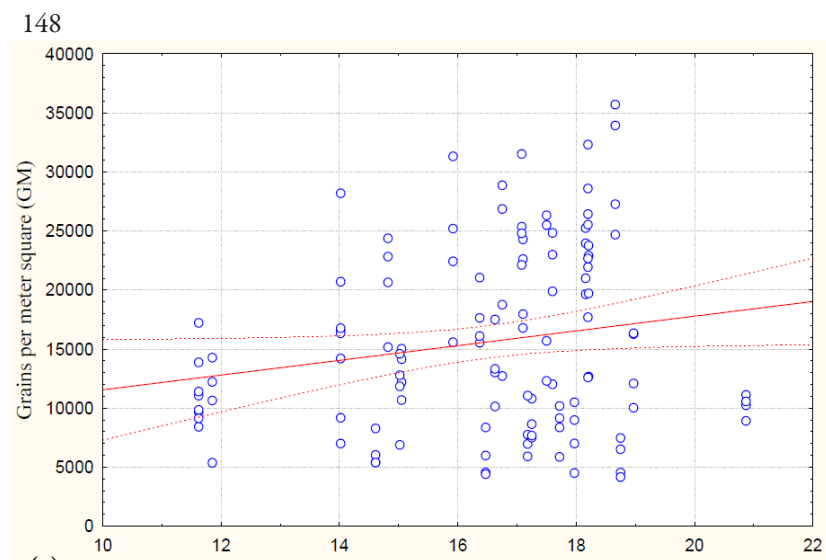

(a)
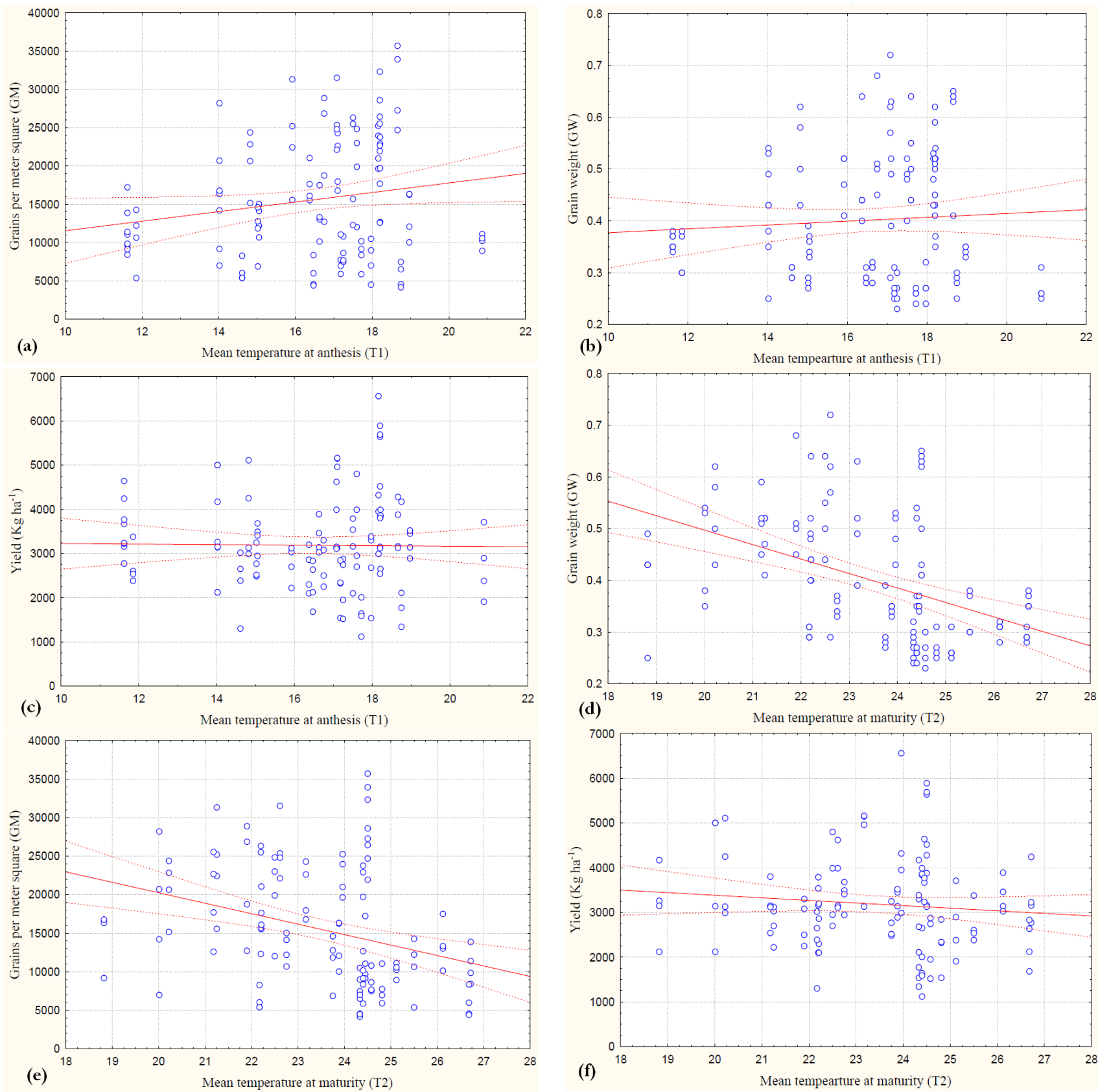

Fig. 1. Scatterplot of Grains per meter square (GM; a and e), Grain weight (GW; b and d) and Yield (Kg ha ${ }^{-1}$; c and f) against mean temperature $\left({ }^{\circ} \mathrm{C}\right)$ at anthesis $(\mathrm{T} 1)$ and at maturity $(\mathrm{T} 2)$

was maximum at optimum temperature, while decreased due to rise in temperature. Increased temperature from germination to maturity may affect grain developmental period of wheat crop. The rising temperature would shorten the period of grain filling in wheat (Wheeler et al., 1996).

Solar radiation might be an important environmental factor which brings positive changes in the crop growth by altering leaf architecture and light partitioning. Similarly, solar radiation activates the photosystem by which light reaction of photosynthesis started and electrons generated by photolysis of water moves to produce energy carriers (e.g. NADPH and ATP). The scatterplot regression model showed a positive relationship between GM, GW and grain yield with SR1 and SR2 (Fig. 2). The regression model obtained for GM, GW and yield with SR1 was GM $=-19542.51+29.53(\mathrm{SR} 1), \mathrm{GW}=-0.15+0.0005(\mathrm{SR} 1)$, $\mathrm{Y}=-1516.47+3.9549(\mathrm{SR} 1)$ respectively. The results described that SR1 positively correlated with yield which may because of good source-sink activity. Likewise, positive association found between crop yield parameters (GM, GW and yield) and SR2. The outcomes of the study indicated that increase in solar radiation from emergence till maturity brought a significant impact on yield. The regression model equation showed a direct relationship with SR2 and GM, GW and yield (GM = -21272.63 

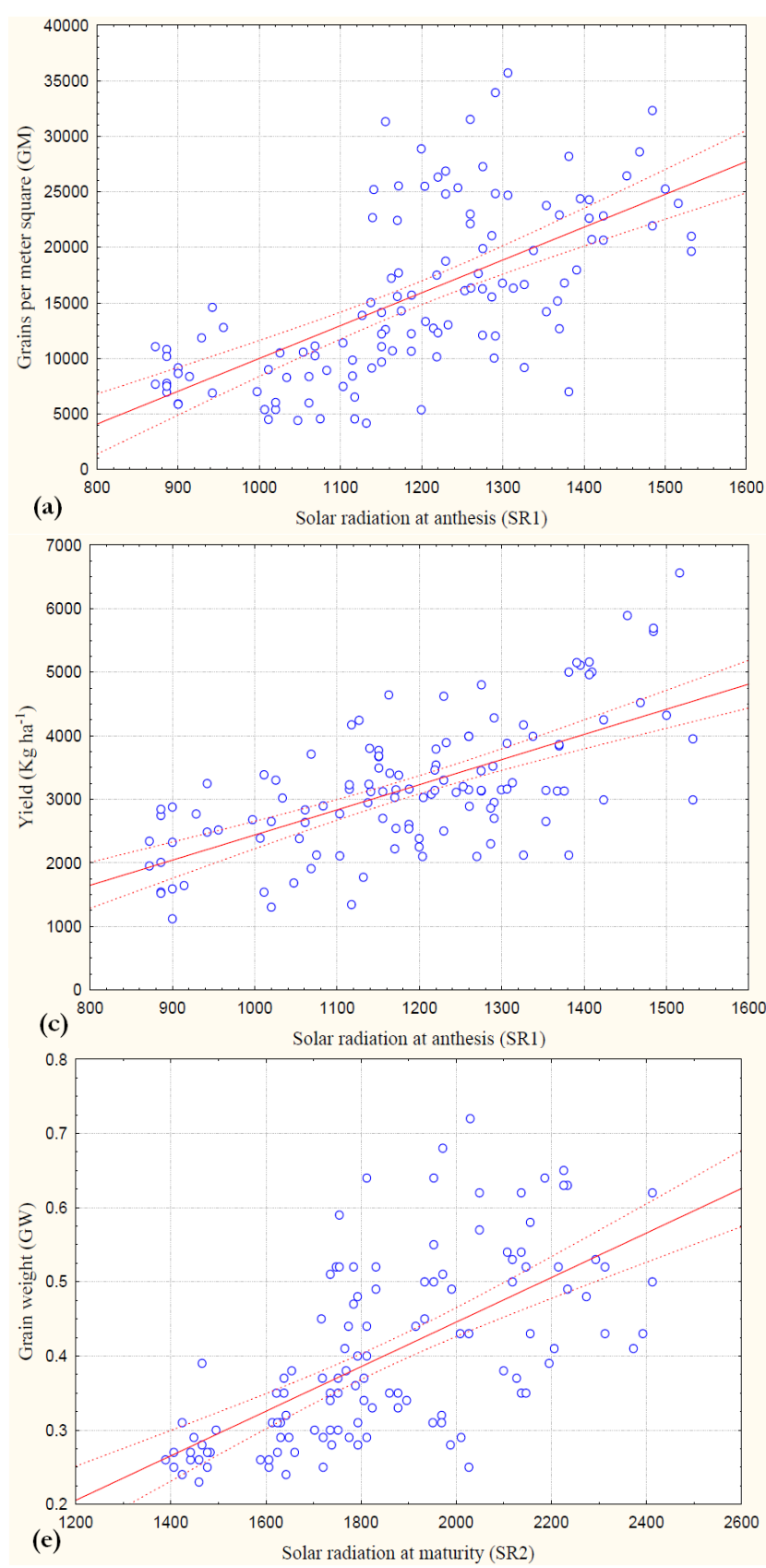

Fig. 2. Scatterplot of Grains per meter square (GM; a and d), Grain weight (GW; b and e) and Yield (Kg ha ${ }^{-1}$; and $\left.\mathrm{f}\right)$ against total solar radiation $\left(\mathrm{MJ} \mathrm{m}^{-2}\right)$ at anthesis $(\mathrm{SR} 1)$ and at maturity (SR2)

$+19.90($ SR2), $\mathrm{GW}=-0.1551+0.0003(\mathrm{SR} 2)$ and $\mathrm{Y}=$ $-1575.8369+2.57($ SR2)). The result showed that with increase in solar radiation GM, GW and yield increased significantly. Similar to the present findings, Richards (2006) reported a considerable effect of seasonal variations of solar radiation on yield. This significant responsive trend of crop toward solar radiation may be due to modification in duration of photosynthesis. Sowing time may be used to bring variability in solar radiation which ultimately effects on the duration of crop growth due to differential partitioning of light. Since if crop is exposed to favorable environmental conditions for longer period of time, it may bring good seed establishment and yield. However, growth
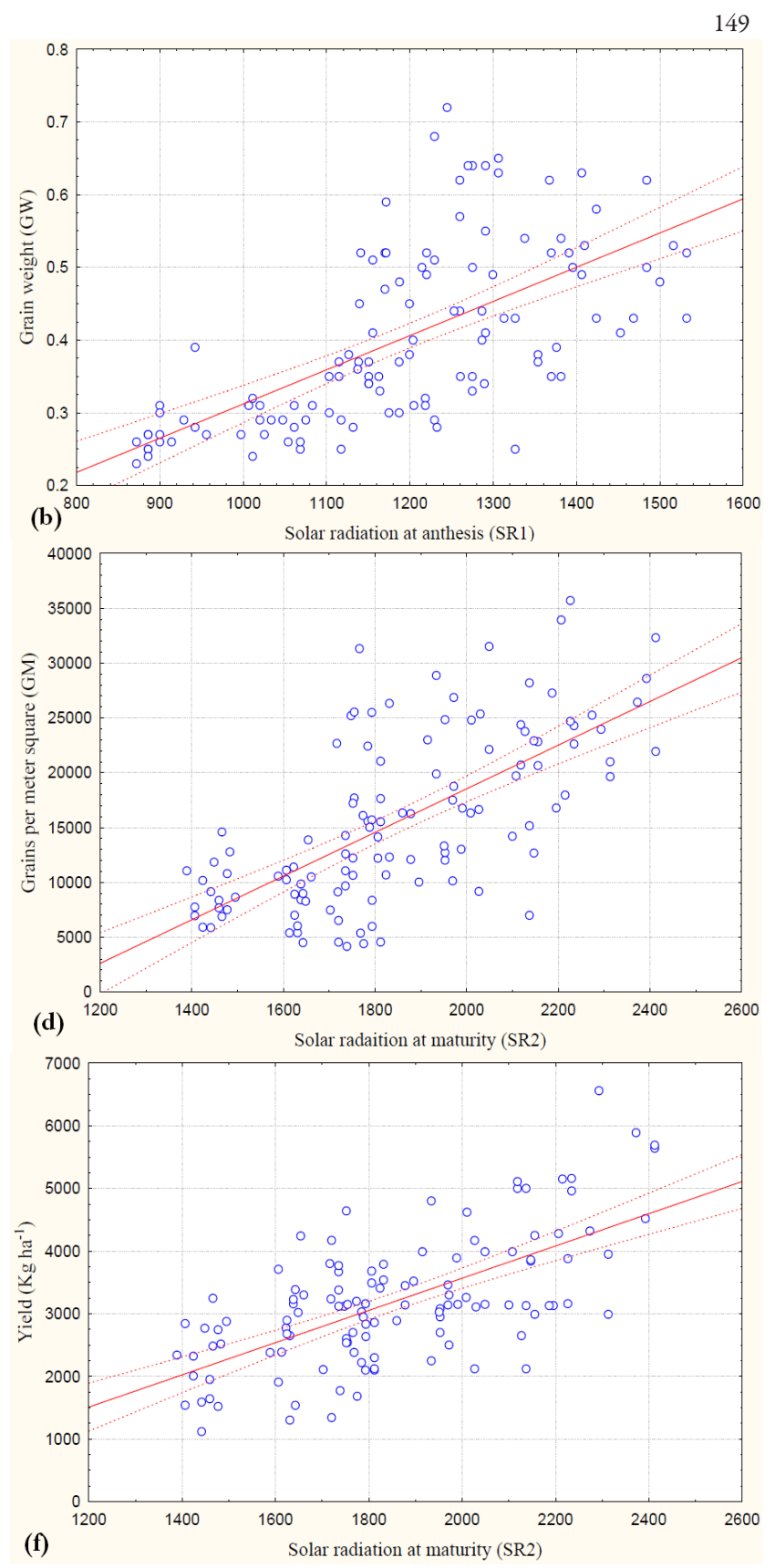

Solar radiation at maturity (SR2) and development would become negative because of reduced solar radiation due to cloud cover. Therefore, results clearly indicated that variations in environmental factors may lead to change in crop yield, thus conclusion of present investigation is in line with the findings of Rodriguez and Sadras (2007).

Photothermal quotient portrayed the combined effect of solar radiation and temperature on crop yield. Grain numbers per meter square (GM), grain weight (GW) and grain yield $\left(\mathrm{Kg} \mathrm{ha}^{-1}\right)$ were positively related to PTQ1 with $\mathrm{R}^{2}$ of $0.88,0.66$ and 0.59 respectively. The regression equation indicated that with unit change in PTQ1, GM, GW and yield increased at the rate of 314.20, 0.0049 

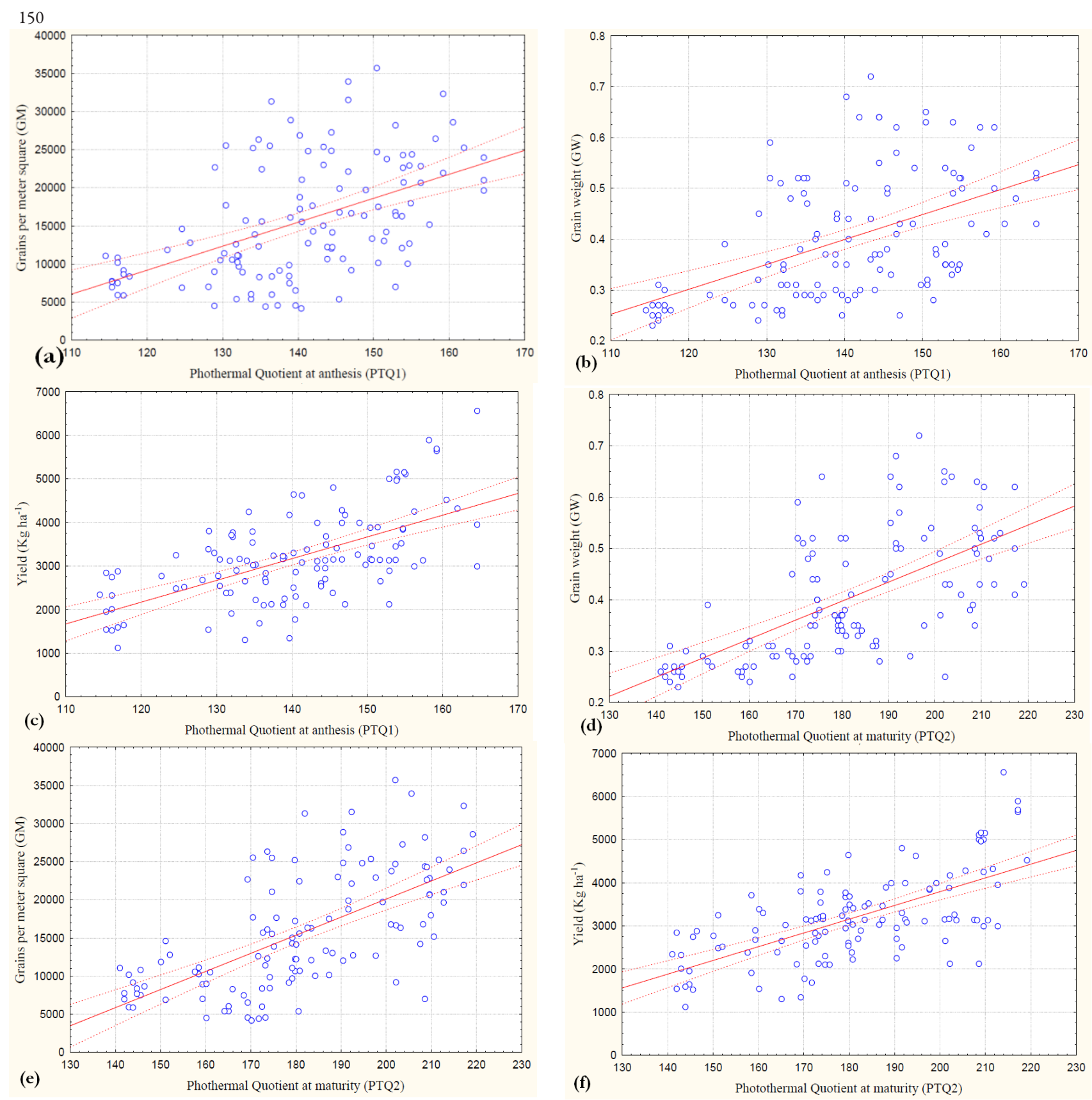

Fig. 3. Scatter plot of Grains per meter square (GM; a and e), Grain weight (GW; b and d) and Yield (Kg ha ${ }^{-1}$; $\mathrm{c}$ and $\left.\mathrm{f}\right)$ against Photothermal Quotient $\left(\mathrm{MJ} \mathrm{m}^{-2} \mathrm{day}^{-1}{ }^{\circ} \mathrm{C}^{-1}\right)$ at anthesis (PTQ1) and at maturity (PTQ2)

and 49.88 respectively. The regression model obtained between PTQ1 and yield components clearly indicated that PTQ1 determined the GM, GW and yield positively if all other resources remained optimum throughout crop growth period. The regression model obtained was $\mathrm{GM}=-28518.88+314.20(\mathrm{PTQ} 1), \mathrm{GW}=-0.287+$ 0.0049 (PTQ1) and $\mathrm{Y}=-3814.91+49.88(\mathrm{PTQ} 1)$ at 0.95 confidence interval (Fig. $3 \mathrm{a}-\mathrm{c}$ ). The scatterplot obtained for PTQ2 indicated a positive correlation between grain numbers per meter square (GM), grain weight (GW) and grain yield $\left(\mathrm{Kg} \mathrm{ha}^{-1}\right)$ and PTQ2 (Fig. $3 \mathrm{~d}$-f). The regression models obtained between PTQ2 and yield parameters depicted that PTQ is determinant factor which affected yield significantly $(\mathrm{GM}=-27382.86+237.40(\mathrm{PTQ} 2)$, $\mathrm{GW}=-0.27+0.0037(\mathrm{PTQ} 2)$ and $\mathrm{Y}=-2582.43+31.87$ (PTQ2). Similarly, PTQ from emergence to maturity determined the overall impact of climate variables on crop growth. Therefore, PTQ available to crop for late planting windows was recorded minimum. Hence, yield GM, GW and yield recorded for late planting windows remained significantly lower. Significant positive association observed between grains $\mathrm{m}^{-2}$ with PTQ1 and PTQ2 $\left(\mathrm{R}^{2}=\right.$ 0.97 and $\mathrm{R}^{2}=0.90$ respectively). The maximum value of PTQ (217.66) recorded for early sowing may be due to favorable environmental conditions throughout crop life cycle. Thus, the present results correspond with the find- 
ings of Oritz-Monasterio et al. (1994). A positive linear tend recorded for Grain weight (GW) and photothermal quotient. The maximum grain weight recorded under maximum PTQ availability from emergence to maturity. Similar findings have been reported, concluding that photothermal quotient affect grain weight decisively provided all other resources optimum throughout life cycle of crop (Ahmed et al., 2011a; Khichar and Niwas, 2007). Yield was strongly linked with PTQ1 and PTQ2 (Fig. 3). The yield was higher under maximum photothermal quotient, which dropped significantly due to decrease in PTQ. This declining trend may because of unavailability of optimum environmental conditions. The present results were at par with the findings of Abbate et al. (1997). Photothermal quotient at maturity, GW and grain yield were positively correlated, as high temperature thought to be a factor that accelerates the ending of crop cycle (Giulioni et al., 1997). However, work like association of photothermal quotient models with grain developments and yield components needs to be documented in order to build a comprehensive model between photothermal quotient and crop growth and development. Since, PTQ elaborated the combined effect of temperature and solar radiation on crop yield it may be considered as limiting factor which may control overall crop growth.

\section{Conclusions}

Use of environmental resources such as temperature and solar radiation by adaptation strategies can increase yield. Therefore, adaptability of Wheat genotype based upon its relationship with PTQ for a particular climate zone can be recommended to minimize losses in the yield due to extreme climatic events.

\section{Acknowledgements}

The authors express special thanks to HEC (Higher Education Commission, Islamabad, Pakistan) for the financial support to complete this research work.

\section{References}

Abbate PE, Andrabe FH, Culot JP, Binrabon PS (1997). Grain yield in wheat: Effects of radiation during spike growth period. Field Crop Res 54(2-3):245-257.

Ahmed M, Hassan FU, Aslam MA, Akram MN, Akmal M (2011a). Regression model for the study of sole and cumulative effect of temperature and solar radiation on wheat yield. African J Biotec 10(45):9114-9121.

Ahmed M, Hassan FU, Razzaq A, Akram MN, Aslam M, Ahmad S, Zia-ul-Haq M (2011b). Is photothermal quotient determinant factor for spring wheat yield? Pak J Bot 43(3):1621-1622.

Ahmed M, Hassan FU, Asim M, Aslam MA, Akram MN (2010). Correlation of photothermal quotient with spring wheat yield. African J Biotec 9:7869-7852.

Akcura M, Kaya YK, Taner S (2005). Genotype-Environment Interaction and Phenotypic Stability Analysis for Grain Yield of Durum Wheat in the Central Anatolian Region. Turkish J Agric 29:369-375.

Allen RG, Pereira LS, Raes D, Smith M (1998). Crop evapotranspiration. Guidelines for computing crop water requirements. Food and Agriculture Organization of the United Nations, Rome.

Bahar B, Yildirim M, Barutcular C, Genc I (2008). Effect of canopy temperature depression on grain yield and yield components in bread and durum wheat. Not Bot Horti Agrobo 36(1):34-37.

Dawson IA, Wardlaw IF (1989). The tolerance of wheat to high temperature during reproductive growth.III. Booting and Anthesis. Austr J Agric Res 40:965-980.

Dumoulin V, Ney B, Eteve G (1994) Variability of seed and plant development in pea. Crop Sci 34:992-998.

Feiziasl V, Jafarzadeh, Amri A, Mousavi SB, Chenar MA (2010). Analysis of Yield Stability of Wheat Genotypes Using New Crop. Properties Balance Index (CPBI) Method. Not Bot Horti Agrobo 38(1):228-233.

Gate P (2007). Le blé face au changement climatique. Perspectives Agric 336:20-56.

Giulioni L, Wery J, Tardieu F (1997). Heat stress-induced abortion of buds and flowers in pea: is sensitivity linked to organ age or to relations between reproductive organs. Ann Bot 80:159-168.

IPCC (2001). Climate Change (2001). The Scientific Basis, 881 p. In: Houghton JT, Ding Y, Griggs DJ, Noguer M, Van der Linden PJ, Dai X, Maskell K, Johnson CA (Eds.). Cambridge University Press, Cambridge, UK.

IPCC (2007). Summary for policymakers, 7-22 p. In: Parry M, Canziani O, Palutikof J, Van der Linden P, Hanson C (Eds.). Climate change 2007: impacts, adaptation and vulnerability. Contribution of Working Group II to the Fourth Assessment Report of the Intergovernmental Panel on Climate Change. Cambridge: Cambride University Press.

Kalra N, Chakraborty D, Sharma A, Rai HK, Jolly M, Cher S, Ramesh KP, Bhadraray S, Barman D, Mittal RB, Lal M, Sehgal M (2008). Effect of increasing temperature on yield of some winter crops in northwest India. Current Sci 94:8288.

Khichar ML, Ram N (2007). Thermal effect on growth and yield of wheat under different sowing environments and planting systems. J Agric Res 41.

Li S, Wheelerb T, Challinorc A, Lind E, Jud H, Xud Y (2010). The observed relationships between wheat and climate in China. Agric Forest Meteor 150:1412-1419.

Lobell DB, Field CB (2007). Global scale climate-crop yield relationships and the impact of recent warming. Environ Res Lett 2:1-7.

Loomis RS, Amthor JS (1996). Limits to yield revisited, 76-89 
152

p. In: Reynolds MP Rajaram, McNab A (Eds.). Increasing yield potential in wheat: Breaking the barriers. CIMMYT.

Mohsen B, Yamada T (1991). Screening spring wheat genotypes (triticum sp.) for seedling emergence under optimal and suboptimal temperature conditions, Japan J Breed 41:381387.

Nalley LL, Rew PB, Sayre K (2009). Photothermal Quotient specifications to improve wheat cultivar yield component models. Agron J 101:556-563.

Ormerod SJ, Marshall EJP, Kerby G, Rushton SP (2003). Meeting the ecological challenges of agricultural change: editors' introduction. J Appl Eco 40:939-946.

Ortiz-Monasterio RJI, Dhillon SS, Fischer RA (1994). Date of sowing effects on grain yield and yield components of irrigated spring wheat cultivars and relationships with radiation and temperature in Ludhiana, India. Field Crops Res 37:169-184.

Rodriguez D, Sadras VO (2007). The limit to wheat water-use efficiency in eastern Australia. I. Gradients in the radiation environment and atmospheric demand. Aust J Agric Res
58:287-302.

Richards RA (2006). Physiological traits used in the breeding of new cultivars for water-scarce environments. Agric Water Manag 80:197-211.

Statsoft Inc (2007). STATISTICA (data analysis software system) version 8.0. www.statsoft.com.

Wang X, Cai J, Jiang D, Liu F, Dai T, Cao V (2011). Pre-anthesis high-temperature acclimation alleviates damage to the flag leaf caused by post-anthesis heat stress in wheat. J Plant Physiol 168(6):585-593.

Wheeler TR, Hong TD, Ellis RH, Batts GR, Morison JIL, Hadley $P(1996)$. The duration and rate of grain growth, and harvest index, of wheat (Triticum aestivum L.) in response to temperature and $\mathrm{CO}_{2}$.J Exp Bot 47:623-630.

You L, Rosegrant MW, Wood S, Sun D, (2009). Impact of growing season temperature on wheat productivity in China. Agric Meteor 149:1009-1014. 